\title{
As complexidades da cibercultura em Pierre Lévy e seus desdobramentos sobre a educação
}

\author{
Dário Lissandro Beutler ${ }^{1}$, Adriano Canabarro Teixeira ${ }^{2}$ \\ ${ }^{1}$ Instituto Federal de Educação, Ciência e Tecnologia do Rio Grande do Sul (IFRS) \\ Câmpus Erechim - Rua Domingos Zanella, 104 - Três Vendas - Erechim, RS - Brasil. \\ ${ }^{2}$ Universidade de Passo Fundo, Instituto de Ciências Exatas e Geociências. \\ Campus Universitário - Bairro São José - Passo Fundo, RS - Brasil. \\ dario.beutler@erechim.ifrs.edu.br, teixeiradupf.br
}

\begin{abstract}
Resumo. O termo cibercultura permeia discursos em várias áreas da sociedade contemporânea, da área educacional, negócios até a política. $O$ tema é relevante em função de sua complexidade e de suas implicações para as mudanças culturais que atingem todos os setores da sociedade na atualidade. Este artigo tem como objetivo analisar algumas complexidades da cibercultura tendo como base três obras do estudioso francês Pierre Lévy. Entende-se que compreendendo mais profundamente essas complexidades, mais facilmente se poderá envolver as pessoas e instituições educativas a participarem da construção dos processos positivos possibilitados pela cibercultura.
\end{abstract}

\begin{abstract}
The term cyberculture permeates discourses in different areas of contemporary society in educational area, business and even in politics. The subject is relevant because of its complexity and its implications for the cultural changes that affect all sectors of Society currently. This article aims to analyze some complexities of cyberculture based on three works of the French researcher Pierre Lévy. It is understood that with deeper understanding of these complexities, the easier will be the engagement of people and educational institutions into participate in the construction of the positive processes made possible by cyberculture.
\end{abstract}

\section{Introdução}

Vários autores se dedicam a caracterizar a sociedade contemporânea. Dentre eles, destaca-se Pierre Lévy, sociólogo e filósofo francês, nascido em Túnis (Tunísia) e é um dos mais proeminentes pensadores da cultura virtual contemporânea. Lévy (1999) define a cibercultura como o conjunto de técnicas materiais e intelectuais, de práticas, atitudes, modos de pensamento e valores que se desenvolvem juntamente com o crescimento do ciberespaço, entendido como sinônimo de rede, o novo meio de comunicação que surge da interconexão mundial dos computadores. Estas definições apresentadas de ciberespaço e de cibercultura são plausíveis para a introdução do tema, porém insuficientes para uma adequada compreensão das complexidades por elas carregadas. 
A partir do conceito de cibercultura apresentado, pode-se imaginar que em algum momento da história criou-se o ciberespaço e somente após é que teria surgido a cibercultura. Pensando desta forma, cria-se uma visão equivocada e tecnicista da cibercultura. Equivocada porque o próprio conceito de (ciber) cultura não é algo estático que surge em um momento específico como, por exemplo, com o surgimento da internet, e tecnicista porque estaria associada apenas à estrutura física e técnica da internet. Lévy $(1993,1999)$ defende a ideia de que o próprio ciberespaço já é fruto de um verdadeiro movimento social da (ciber) cultura, pois o computador pessoal foi criado por jovens californianos à margem do sistema que queriam instituir novas bases para a informática para revolucionar a sociedade. Junto com o computador pessoal, as redes digitais surgiram pela liderança de grupos da juventude metropolitana escolarizada com suas palavras de ordem e suas aspirações coerentes que representavam fortes correntes culturais e buscavam alcançar a comunicação recíproca e a inteligência coletiva.

A compreensão da dinâmica da cibercultura e da lógica do ciberespaço muda o modo de perceber certos conceitos e o que eles de fato podem representar para o futuro da humanidade. Lévy (1993) afirma que a técnica é uma das dimensões fundamentais da cibercultura e do ciberespaço, mas o que está em jogo é a transformação do mundo humano por ele mesmo. O autor destaca que não há nenhuma distinção real bem definida entre o homem e a técnica, nem entre a vida e a ciência. Essas distinções são criadas para fins de análise, mas não se deve tomar esses conceitos para fins precisos como sendo regiões do ser radicalmente separadas. Segundo ele, não podemos exprimir a técnica como uma condenação moral ou como um fenômeno separado dos objetivos de mudança do coletivo e do mundo das significações (da cultura).

\section{A Cibercultura}

Para compreender melhor a cibercultura a partir de uma visão imbricada de técnica, política e projetos culturais, Lévy (1993) considera importante perceber que a informática e o ciberespaço são produtos de uma evolução histórica do que ele denomina de tecnologias intelectuais ou tecnologias da inteligência. Para o autor, ao longo da história, o ser humano criou três grandes tipos de tecnologias intelectuais para expressar a sua inteligência: a oralidade, a escrita e a informática. Entender a evolução das tecnologias intelectuais é fundamental para compreender a cibercultura, pois elas desfazem e refazem as ecologias cognitivas contribuindo para a derivação das fundações culturais que comandam a nossa apreensão do real. Assim, serão apresentados os aspectos mais relevantes de cada uma das tecnologias intelectuais.

Para Lévy (1993), a oralidade remete ao papel da palavra antes de os grupos humanos adotarem a escrita. Neste contexto, a palavra tinha como função básica a gestão da memória social e não apenas a comunicação prática cotidiana. Nessa sociedade, quase toda a base cultural está fundada sobre as lembranças dos indivíduos, a inteligência está muitas vezes identificada com a memória, sobretudo auditiva. Assim, a dramatização, a personalização e os artifícios narrativos não visam apenas dar prazer a um espectador, mas são também condições de perenidade de um conjunto de proposições em uma cultura oral. Para isso, são usadas as memórias musicais e sensoriomotoras como narrativas dramáticas, agradáveis de ouvir e de forte carga emotiva, pois essas atividades servem também de auxiliares da memória semântica. 
Além disso, o tempo da oralidade tem um caráter cíclico, a passagem do tempo supõe um incessante movimento de recomeço, é o tempo da mudança, as narrativas se alteram ao sabor das circunstâncias e a transmissão é sempre recriação.

A segunda tecnologia intelectual definida por Lévy (1993) é a escrita que fez com que a teoria, a lógica e a interpretação dos textos fossem acrescentadas às narrativas míticas do saber humano. As criações do alfabeto, da impressão e dos aperfeiçoamentos da escrita foram essenciais para o estabelecimento da ciência como modo de conhecimento dominante e de registro de mundo. Lévy afirma que a escrita, ao intercalar um intervalo de tempo entre a emissão e a recepção da mensagem, gera uma situação prática de comunicação radicalmente nova, pela primeira vez os discursos podem ser separados das circunstâncias particulares em que foram produzidos. Assim, quando as mensagens fora de contexto e ambíguas começam a circular, a atribuição de sentido passa a ocupar um lugar central no processo de comunicação. Então o exercício de interpretação passou a ser muito importante. Porém o sentido dado ao texto através da interpretação pode muitas vezes ter pouca relação com o dos autores daquele registro. A notação escrita torna mais cômoda a conservação e a transmissão de representações modulares separadas, independentes de ritos e narrativas. Assim os indivíduos de culturas escritas têm tendência a pensar por categorias enquanto que as pessoas de culturas orais captam em primeiro lugar as situações. À medida que passamos da ideografia ao alfabeto e da caligrafia à impressão, os signos são colocados em ordem sequencial sobre a página, e por isso o tempo também se torna cada vez mais linear e histórico, a história passa a ser efeito da escrita. A impressão fez surgir um novo gênero de apresentação do saber, o método analítico.

Lévy (1993) apresenta a informática como a terceira tecnologia intelectual, representada pelos computadores e as redes digitais. Os computadores possuem uma série de dispositivos materiais e camadas de programas que se recobrem e interfaceiam umas às outras. Essas camadas que são as inovações da informática provêm de outras técnicas como a eletrônica, as telecomunicações, o laser e outras ciências como a matemática, a lógica, a psicologia cognitiva e a neurobiologia. Cada casca sucessiva vem do exterior, é heterogênea em relação à rede de interfaces que recobre, mas acaba tonando-se parte integrante da máquina. É importante destacar que a invenção do computador pessoal veio de fora, não se fez apenas independentemente dos grandes fabricantes da área, mas contra eles. Foi essa inovação imprevisível que transformou a informática em um meio de massa para a criação, a comunicação e a simulação. Não há identidade estável na informática porque os computadores são redes de interfaces abertas a novas conexões, imprevisíveis, que podem transformar radicalmente seu significado e uso.

Juntamente com essas funções é possível uma nova escrita hipertextual que estará mais próxima da montagem de um espetáculo do que da redação clássica, na qual o autor apenas se preocupava com a coerência de um texto linear e estático. Abrindo espaço para uma equipe de autores em uma dinâmica de trabalho coletivo. Lévy (1993) ressalta que os autores do futuro terão como tarefas inventar novas estruturas discursivas, descobrir retóricas ainda desconhecidas do esquema dinâmico, do texto de geometria variável e da imagem animada, em que as cores, o som e o movimento irão se associar para significar. O contexto das novas tecnologias intelectuais terá aspectos similares ao dos grandes impressores do século XVI que eram ao mesmo tempo 
letrados, humanistas, técnicos e exploradores de um novo modo de organização do saber.

A massa de dados digitais disponíveis se infla o tempo todo e quanto mais ela cresce, mais é preciso estruturá-la, cartografá-la e mais as interfaces para encontrar e usar esses dados devem ser aperfeiçoadas. O acesso direto aos dados através do computador permite todas as consultas e distribuições imagináveis, em particular a integração com dispositivos interativos. Além disso, Lévy (1993) destaca a importância da noção de tempo real, criada pelos informatas, que resume bem o espírito da informática, que consiste na condensação no presente e na operação em andamento. A partir dessa concepção, pode-se pensar que a perspectiva histórica, e toda a reflexão crítica teriam desertado da cultura da informática. Entretanto, as novas escritas dinâmicas (hipertextos, composições multimídia, groupwares) podem muito bem reintroduzir certas formas de distância histórica e de trabalho hermenêutico no próprio núcleo da interconexão em tempo real que é intrínseco à informática.

Outra questão que Lévy (1993) aponta é que com as tecnologias intelectuais da informática, a memória está tão fora de nós e tão acessível que é importante refletir se a própria noção de memória ainda é pertinente. O saber informatizado afasta-se da memória, representada pelo saber de cor. A memória, ao informatizar-se, é objetivada a tal ponto que a verdade pode deixar de ser uma questão fundamental, em proveito da operacionalidade e velocidade da localização da informação. Na civilização escrita, o livro e a teoria permaneciam, no horizonte do conhecimento, havia uma estabilidade e unicidade possíveis, as da teoria verdadeira, da explicação correta. Atualmente é temeroso para um indivíduo cogitar sua identificação, mesmo que parcial, com uma única teoria, o conhecimento está em metamorfose permanente e vertiginosa, as teorias cedem terreno aos modelos que não se encontram inscritos no papel, mas rodam no computador e ampliam-se na rede.

Para Lévy, o modelo digital não é lido ou interpretado como um texto clássico, ele geralmente é explorado, de forma interativa, ele é plástico, dinâmico, dotado de certa autonomia de ação e reação, é o conhecimento por simulação. A manipulação dos parâmetros e a simulação de todas as circunstâncias dão ao usuário do programa uma espécie de intuição sobre as relações de causa e efeito presentes no modelo. Em termos cognitivos, se adquire um conhecimento por simulação do sistema modelado, que não se assemelha nem a um conhecimento teórico, nem a uma experiência prática, nem ao acúmulo de uma tradição oral. Os cientistas da psicologia cognitiva criaram a hipótese de que o raciocínio humano cotidiano tem pouca relação com a aplicação de regras da lógica formal. É mais plausível que as pessoas construam modelos mentais das situações ou objetos sobre os quais estão raciocinando e depois explorem as diferentes possibilidades dentro dessas construções imaginárias.

Assim, a simulação através de modelos, pode ser considerada como uma imaginação auxiliada por computador, e é, ao mesmo tempo, uma ferramenta de ajuda ao raciocínio muito mais potente que a lógica formal que se baseava no alfabeto. A simulação (a imaginação, a bricolagem mental, as tentativas e erros) corresponde à etapa da atividade intelectual anterior à exposição racional através de uma teoria que é uma versão mais formalizada de apresentação do saber. A partir da compreensão da dinâmica das tecnologias intelectuais é possível aprofundar o conceito de ciberespaço que é 
elemento potencializador da cibercultura, pois é neste ambiente de tecnologias intelectuais da informática que o mesmo surge e coexiste.

\section{O Ciberespaço}

O ciberespaço, para Lévy (1999), é um dispositivo de comunicação interativo e comunitário, que engloba todas as vantagens e recursos das tecnologias intelectuais da informática. No ciberespaço, o computador não é um centro, e sim um nó, um componente da rede universal calculante. Dessa forma a informática contemporânea está desconstruindo o computador em benefício de um espaço de comunicação navegável e transparente. Neste espaço todas as funções são distribuíveis e cada vez mais distribuídas, tornando-se assim um instrumento privilegiado da inteligência coletiva.

As tecnologias intelectuais da informática e o ciberespaço potencializam o conceito essencial da cibercultura que Lévy (1999) caracteriza como universal sem totalidade. O ciberespaço é universal porque possibilita que qualquer pessoa do mundo independente do tempo e do espaço, dele faça parte, não possui nem um centro e nem uma linha diretriz. Ele aceita a todos, pois se contenta em colocar em contato um ponto qualquer com outro, não importando o significado das entidades relacionadas. $O$ ciberespaço não gera uma cultura do universal porque está em toda a parte, e sim porque sua forma e sua organização implicam, de direito, o conjunto dos seres humanos. Ele é sem totalidade (a totalização é o fechamento semântico, a unidade de razão, a redução ao denominador comum), pois é um universo indeterminado e que tende a manter sua indeterminação, pois cada novo nó da rede de redes em expansão constante pode tornarse produtor de novas informações, imprevisíveis, e, assim, reorganizar uma parte da conectividade global por sua própria conta. Além da ideia do universal sem totalidade, outro aspecto fundamental para a compreensão da cibercultura é o de virtualização, enquanto estado potencial das coisas.

\section{Virtualização}

A virtualidade constitui o traço distintivo da nova face da informação que surge com as tecnologias digitais da informática e do ciberespaço. Lévy (1996) afirma que a digitalização é o fundamento técnico da virtualidade, e que ela não afeta apenas a informação e a comunicação, mas também os corpos, a economia, a sensibilidade e o exercício da inteligência (comunidades virtuais, empresas virtuais, democracia virtual). Apesar de o ciberespaço enquanto infraestrutura técnica ter um papel importante nesse processo trata-se de um fenômeno que ultrapassa amplamente a informatização.

A palavra virtual é muitas vezes empregada para significar aquilo que não existe. Esse conceito gera uma visão equivocada e dicotômica entre o virtual e o real. Nessa visão, o real pressupõe uma efetivação material, uma presença tangível e o virtual passa a significar a pura e simples ausência de existência, uma ilusão. Tal compreensão supõe então que uma coisa deve ser real ou virtual, não podendo possuir as duas propriedades ao mesmo tempo. Lévy (1996) demonstra que na concepção filosófica, o virtual é aquilo que existe apenas em potência e não em ato, então ele não se opõe ao real, mas sim ao atual: virtualidade e atualidade são dois modos diferentes da realidade. A árvore, por exemplo, está virtualmente presente na semente e assim a virtualidade dessa árvore é bastante real (sem que seja, ainda, atual). Pode-se dizer que é virtual toda a entidade 
desterritorializada, capaz de gerar diversas manifestações concretas em diferentes momentos e locais determinados, sem, contudo estar ela mesma presa a um lugar ou tempo em particular, afirma Lévy (1996).

A atualização aparece para Lévy (1996) então como a solução momentânea de um problema, é criação, invenção de uma forma a partir de uma configuração dinâmica de forças e de finalidades. E a virtualização é o movimento inverso da atualização, não é uma desrealização, mas uma mutação de identidade, ou seja, a entidade passa a encontrar sua consistência essencial num campo problemático. Dessa forma, virtualizar uma entidade consiste em descobrir uma questão geral a qual ela se relaciona, em fazer mutar a entidade em direção a essa interrogação. A virtualização de uma empresa, por exemplo, consiste em fazer as coordenadas espaço-temporais do trabalho um problema sempre repensado e não uma solução estável. A atualização vai de um problema para uma solução e a virtualização passa de uma solução dada a um (outro) problema. Dessa forma, a virtualização é um dos principais vetores da criação de realidade.

A invenção de novas velocidades é o primeiro grau da virtualização. Neste contexto, Lévy (1996) relata que a aceleração das comunicações é contemporânea de um enorme crescimento da mobilidade física e trata-se da mesma onda de virtualização. Outra característica do virtual é o chamado efeito moebius que é a passagem do interior ao exterior e do exterior ao interior, como por exemplo, das relações entre privado e público, próprio e comum, mapa e território, autor e leitor. As fronteiras nítidas dão lugar a uma fractalização das repartições, com a passagem à problemática, deslocamento do ser para a questão, é algo que questiona a identidade clássica, pensamento apoiado em definições, determinações, inclusões e exclusões. Por isso, a virtualização é sempre um processo de acolhimento da mudança. Lévy (1996) destaca três casos concretos de virtualização que são a virtualização do corpo, do texto e da economia, dos quais analisaremos os dois primeiros.

Uma visão da virtualização do corpo é que podemos estar ao mesmo tempo aqui e lá devido às técnicas de comunicação e de telepresença. Outra visão é que virtualizamos o corpo, pois os equipamentos de visualização médicos tornam transparente nossa interioridade orgânica, os enxertos e as próteses nos misturam aos outros e aos artefatos. Inventamos hoje maneiras de nos construir, nos remodelar através de dietas, body building, cirurgia plástica e medicamentos. O telefone para a audição, televisão para a visão, telemanipulações para o tato e interação sensório-motora são os dispositivos que virtualizam os sentidos. Vários dispositivos nos permitem perceber as sensações de outra pessoa, em outro momento e outro lugar. Os sistemas de realidade virtual nos permitem experimentar praticamente a experiência sensorial completa de outra pessoa, independente de onde estivermos. Assim como com o corpo, quando compartilhamos uma dose de inteligência e visão de mundo com os que falam a mesma língua, nos associamos virtualmente num só corpo com os que participam das mesmas redes técnicas.

Quanto à virtualização do texto, Lévy (1996) defende que ele é sempre um objeto virtual, abstrato, independente de um suporte específico, atualiza-se em múltiplas versões, traduções, edições, e ao interpretar, dando sentido ao texto aqui e agora, o leitor segue realizando atualizações. Para Lévy (1996) o texto é esburacado, pois tem fragmentos que não compreendemos, não reunimos a outros, que negligenciamos. Desta 
forma, ler é começar a negligenciar. Além disso, quando lemos construímos o sentido do texto e também o relacionamos a outros textos, imagens, afetos e então não é mais o sentido do texto que nos ocupa, mas a direção do nosso pensamento e a culminação de nossos projetos. Quando lemos, em breve nada mais resta do texto, na melhor das hipóteses o que conseguimos é dar um retoque em nossos modelos do mundo, ou seja, quando lemos estamos nos construindo e incorporando o texto em nós. Nesse caso, o texto serve de vetor, de suporte ou de pretexto à atualização de nosso espaço mental. Assim, quanto maior o texto, maior é a ampliação de nosso espaço mental.

Com relação à virtualização do texto é importante analisar as características do hipertexto que é o texto emergente da simbiose com as tecnologias intelectuais da informática e redes. Lévy (1999) afirma que o hipertexto está em oposição a um texto linear e como um texto estruturado em rede é uma nova arte da edição e da documentação. No texto convencional, o texto inicial já está lá, realizado integralmente e o hipertexto por sua vez é uma matriz de textos potenciais (possíveis), alguns deles vão se realizar somente na interação com o usuário. Lévy (1999) destaca que o virtual do texto só ocorre com a entrada da subjetividade humana no circuito, quando em um mesmo movimento surgem a indeterminação de sentido e a propensão do texto a significar, tensão que uma atualização, ou seja, uma interpretação resolverá na leitura. Neste sentido, o hipertexto opera a virtualização do texto, pois permite hierarquizar e selecionar áreas de sentido, tecer ligações entre essas zonas e também conectar o texto a outros documentos.

O hipertexto acessível por meio de uma rede de computadores é um poderoso instrumento de escrita-leitura coletiva, afirma Lévy (1999). Ele se torna importante pois através de sua digitalização e suas novas formas de apresentação nos dá acesso a outras maneiras de ler e de compreender. Assim, se o computador for considerado como uma ferramenta para produzir textos clássicos, ele será apenas um instrumento mais prático, mas se considerarmos o conjunto de todos os textos que o leitor pode divulgar automaticamente com um computador e uma rede digital, entramos em um novo universo de criação e de leitura dos símbolos. Para Lévy (1996), o uso da informática para produção de hipertextos produz uma mudança cultural, ou seja, permite o surgimento de novos gêneros ligados à interatividade. $\mathrm{O}$ hipertexto com suporte digital permite novos tipos de leituras (e escritas) coletivas, que consistem em uma mudança da leitura individual de um texto preciso para a navegação em vastas redes digitais em que um grande número de pessoas anota, aumenta e conecta os textos uns aos outros. $\mathrm{O}$ hipertexto que está no ciberespaço reconstitui de outro modo e numa escala infinitamente superior, a copresença da mensagem e de seu contexto vivo que caracteriza a comunicação oral. Nesse tipo de texto, os critérios mudam e se reaproximam daqueles do diálogo ou da conversação. Nestes textos, a pertinência em função do momento, a brevidade e a eficiência são critérios importantes.

O hipertexto objetiva, operacionaliza e amplia a potência do coletivo e a identificação cruzada do leitor e do autor. Neste contexto toda a leitura torna-se um ato de escrita. Os hipertextos nas redes digitais não têm fronteiras nítidas, não há mais um texto discernível e individualizável, é um texto que está mais próximo do próprio movimento do pensamento. A interpretação desse texto ou a produção de sentido surgem de efeitos de pertinência locais, surgem de uma trajetória de eficácia ou prazer. Não existe o interesse mais pelo que pensou um autor, mas pedimos ao texto para nos 
fazer pensar, aqui e agora, o texto precisa alimentar nossa inteligência em ato. Desta forma, Lévy (1996) afirma que o uso dos suportes dinâmicos da informática pode suscitar a invenção de novos sistemas de escrita que explorariam melhor as novas potencialidades do hipertexto digital. Estamos na era da escrita do texto digitalizado, fluído, reconfigurável, de modo não linear e que cada participante é um autor em potencial. Dessa forma, longe de aniquilar o texto, a virtualização possibilita novas formas de escrita e leitura. É praticamente uma nova invenção da escrita que passa a apresentar traços da oralidade.

\section{As complexidades da cibercultura}

A partir das questões apresentadas em que Pierre Lévy caracteriza a cibercultura, pode-se perceber que a sociedade contemporânea se encontra frente a uma série de novas complexidades potencializadas pela mudança de pensamento que surgiu principalmente com a criação e uso das tecnologias intelectuais da informática e do ciberespaço. $\mathrm{O}$ termo complexidade aqui se refere às questões ou situações que surgem das mudanças da sociedade e implicam direta ou indiretamente na realidade de pessoas e instituições. Mas, como geralmente são situações novas, muitas vezes não conseguimos ter a real compreensão nem tampouco da dimensão das implicações inerentes. Desta forma, entende-se por complexidade, neste artigo, todas as novas questões e dilemas que surgem e que temos dificuldades de enfrentá-las ou resolvê-las principalmente por serem novas e mais difíceis de serem compreendidas.

Um grande equívoco na tentativa de compreender a cibercultura é imaginar que ela é apenas um movimento que surgiu exclusivamente de um grupo separado de informatas que criou os computadores e as redes digitais. Dessa forma, fica prejudicada a percepção da cibercultura e ciberespaço como fenômenos universais e assim não existe interesse em participar de seus processos, já que os mesmos não estariam relacionados à sua realidade e sim apenas à realidade dos informatas. Ainda neste mesmo pensamento, imagina-se que a cibercultura surgiu com a criação e uso das redes digitais. Esta é uma visão muito parcial e tecnicista de cibercultura. É necessário inverter essa lógica e perceber que foi a (ciber) cultura humana, que é dinâmica e está sempre em evolução, que fez surgir os computadores e o ciberespaço através de um verdadeiro movimento social com o objetivo de revolucionar a sociedade. Esse movimento, originado principalmente pela juventude não satisfeita com o sistema, teve como objetivo, através dos computadores e dos protocolos de rede, um processo de emancipação humana. Pois, dando acesso aos computadores para um grande número de pessoas tinha-se como objetivo a apropriação dos meios de produção pelos até então consumidores, já que os computadores pessoais passaram a ser as principais ferramentas da atividade econômica. E neste mesmo movimento, com a criação das redes de computadores tinha-se como objetivo um desejo da democratização da comunicação recíproca e a criação de uma infraestrutura de suporte ao desenvolvimento da inteligência coletiva.

Quanto mais compreendermos que o ciberespaço é parte de um processo que busca a emancipação do homem e não a separação entre eles, provavelmente mais perceberemos o potencial deste novo espaço de comunicação. Compreender que a sociedade foi historicamente criando e manipulando diferentes tecnologias intelectuais que modificaram a forma e as ferramentas para manipular o conhecimento é outra 
complexidade da cibercultura. Para poder participar ativamente explorando as potencialidades da cibercultura é necessário compreender que já passamos pelas sociedades da oralidade e da escrita e que hoje estamos na sociedade das tecnologias intelectuais da informática e do ciberespaço que acaba por virtualizar as duas primeiras. Isto quer dizer que temos novas formas de manipular o saber, temos novos recursos para a criação, a comunicação e a simulação. Serão essas as tarefas que esperam os autores do futuro.

Isto não quer dizer que abandonamos completamente a oralidade e a escrita, pelo contrário, elas coabitam e são potencializadas pelas novas possibilidades das tecnologias intelectuais da informática, configurando-se em novas escritas dinâmicas como os hipertextos, as composições multimídia, as simulações e o software para possibilitar o trabalho em grupo (groupwares). Buscando uma perspectiva do tempo mais próximo do tempo real, nos preocupando menos com uma unicidade da verdade, da versão correta e mais com a operacionalidade e com os modelos que rodam no computador que raramente são definitivos.

Outra complexidade da cibercultura é a quantidade e a riqueza de recursos que o ciberespaço oferece para quem verdadeiramente conseguir compreender seu significado e as suas potencialidades. Quando se compreende que o ciberespaço não é apenas a infraestrutura material da comunicação digital, mas também todas as informações que ela abriga e os seres humanos que navegam e alimentam esse universo, se percebe que o mesmo consiste em dispositivo de comunicação interativo e comunitário sem precedentes, e principalmente é um instrumento privilegiado para o desenvolvimento da inteligência coletiva. O ciberespaço apresenta o conceito do universal sem totalidade, que quando compreendido com maior profundidade, se percebe que o mesmo se constitui em um passo da evolução do homem.

Além das complexidades já apresentadas, a virtualização consiste em uma das questões mais distintivas que surgem com a informática e o ciberespaço. A digitalização potencializa em grande medida a virtualidade, porém ela ultrapassa amplamente a informatização. Para explorar as potencialidades da complexidade da virtualização é necessário não confundir o seu significado como sendo o oposto do real. A virtualização não consiste em trabalhar com o irreal, e sim com a passagem à problemática, buscando o deslocamento das pessoas para a questão, ou seja, é um processo que questiona a identidade clássica. Dessa forma, quando se compreende mais profundamente a ideia da virtualização como sendo sempre um processo de acolhimento da mudança, mais facilmente as pessoas se darão conta que podem participar da construção de processos positivos possibilitados pela virtualização e pela cibercultura. Dessa forma, pode-se compreender a virtualização como a possibilidade de perceber o mundo e transformá-lo.

$\mathrm{Na}$ onda da virtualização surgem alguns casos concretos que tornam a sociedade mais complexa como, por exemplo, a virtualização do corpo e do texto. Uma das principais questões da virtualização do corpo é que podemos estar ao mesmo tempo aqui e lá devido às técnicas de comunicação e de telepresença. Dessa forma a virtualização do corpo não pode ser entendida como uma desmaterialização do corpo, ou seja, aquela ideia de que com a informática e o ciberespaço nós ficaríamos apenas em frente ao computador e praticamente não usaríamos mais o corpo não se concretizou. $\mathrm{O}$ que 
aconteceu foi o contrário, assim como com o ciberespaço podemos estar rapidamente em vários lugares, queremos fazer isso com o nosso corpo físico também. Em nenhum outro tempo a mobilidade do ser humano foi tão grande. Esse interesse do ser humano aumentou também na questão de experimentar sensações cada vez mais radicais com o corpo, e também, assim como vemos que o nosso sangue está hoje desterritorializado, irriga um corpo coletivo, assim também estamos virtualmente num só corpo com as outras pessoas do ciberespaço.

Outra complexidade ligada ao virtual é a virtualização do texto que tem a sua potencialidade aumentada com o uso das tecnologias intelectuais da informática na criação e manipulação dos hipertextos. A complexidade está em compreender que o texto nas redes (hipertexto) tem outra estrutura e outro significado que o texto tradicional. Os hipertextos abertos acessíveis por meio de uma rede de computadores são poderosos instrumentos de escrita-leitura coletiva e, além disso, suas novas formas de apresentação nos permitem outras maneiras de ler e de compreender. Assim, o hipertexto operacionaliza e amplia a potência do coletivo e a identificação cruzada do leitor e do autor, permitindo que toda a leitura torne-se um ato de escrita. Neste caso, a complexidade é que não existe mais distinção entre autores e leitores.

\section{Considerações Finais}

Este artigo apresentou complexidades da cibercultura que consideramos importantes para a melhor compreensão da sociedade contemporânea e também da educação neste contexto. A partir dos estudos de Pierre Lévy foram discutidas algumas questões que fazem parte do contexto da cibercultura e que tornam a sociedade atual mais complexa.

Neste sentido, para analisarmos a cibercultura e a sua própria relação com as instituições, principalmente educativas, poderíamos formular os seguintes questionamentos: As instituições educativas estão preparadas para acolher e tratar das novas questões que surgem com a cibercultura? As escolas estão organizadas para trabalhar segundo o princípio do universal sem totalidade do ciberespaço? A partir destes questionamentos percebe-se que grande parte das instituições educativas, na maioria das vezes, não está preparada e estruturada para dar conta de muitas das complexidades da cibercultura. Um possível motivo para essa inadequação é que as mesmas surgiram e estão há séculos baseadas nas tecnologias intelectuais da escrita que são completamente diferentes das tecnologias da informática.

Para que os profissionais das instituições educativas possam melhorar o seu trabalho como educadores é imprescindível que os mesmos estejam dispostos a compreender mais profundamente os conceitos e implicações da cibercultura.

\section{Referências}

LÉVY, P. (1993). As tecnologias da Inteligência: o futuro do pensamento na era da informática. Rio de Janeiro: Ed. 34.

LÉVY, P. (1996). O que é o virtual? São Paulo: Ed. 34.

LÉVY, P. (1999). Cibercultura. São Paulo: Ed. 34 